\title{
Radiation oncology: overview and recent advances
}

\author{
${ }^{1} \mathrm{M}$ Dahele, ${ }^{2} \mathrm{~S}$ Senan \\ ${ }^{1}$ Radiation Oncologist; ${ }^{2}$ Professor of Clinical Experimental Radiotherapy, Department of Radiation Oncology, VU University Medical Center, \\ Amsterdam, the Netherlands
}

\begin{abstract}
Most patients with cancer will be looked after by a diverse team made up of members from community- and hospital-based services. This team will include radiation oncologists. Radiotherapy is an important part of radical or palliative management in about $50 \%$ of patients with cancer. In recent years the specialty of radiation oncology has seen rapid advances in physics and technology, several of which are now having an impact in the clinic where they are helping to realise newer and more effective treatment options. The purpose of this article is to highlight these advances for non-radiation oncologists, with examples of where and how they are changing treatment for patients. The necessity to evaluate and implement high-technology radiotherapy in a cost-efficient manner is discussed.
\end{abstract}

\author{
Correspondence to $M$ Dahele \\ Department of Radiation Oncology, \\ vU University Medical Center, \\ De Boelelaan III7, \\ 108I HV Amsterdam, \\ The Netherlands
}

tel. +3I 2044404 I

e-mail m.dahele@vumc.nl

KEYWORDS Image-guided radiotherapy, intensity-modulated radiotherapy, radiation oncology, radiotherapy, stereotactic radiotherapy, volumetric-modulated arc therapy

DECLARATION OF INTERESTS The VU University Medical Center has a research collaboration with Varian Medical Systems, Palo Alto, California, USA.

\section{INTRODUCTION}

Cancer treatment is typically multidisciplinary, and radiotherapy (RT) is a key component in the management of as many as $50 \%$ of patients.' Radiotherapy can be used as single treatment modality, for example high-dose stereotactic body radiotherapy (SBRT) for early-stage non-small-cell lung cancer (NSCLC), or as part of a multimodal strategy such as organ-preserving concurrent chemo-radiation for head and neck cancer or chemoradiation followed by surgery for locally advanced rectal cancer. Treatments have generally been defined as radical when they are given with curative intent, or palliative when designed to relieve symptoms. However, the distinction between the two is increasingly blurred, with improvements in survival the aim of many palliative treatments ${ }^{2,3}$ and an appreciation that for some tumour sites radical treatments cure a minority of patients. ${ }^{4}$

The history of modern RT dates back about 100 years. Understanding of how RT works and its interaction with tumours and normal tissues is still incomplete. The latter is made more difficult by the fact that late effects in normal tissues can sometimes take several years to appear and there is currently a lack of reliable, predictive biomarkers for toxicity and efficacy. As a result, there remains a necessary element of empiricism in the design of RT treatment schedules. The vast majority of RT treatments use external beam RT (EBRT), which is characterised by high-energy $\mathrm{X}$-ray photons delivered to the patient from a source outside the body, typically a linear accelerator. ${ }^{5}$ This paper therefore focuses on EBRT. It does not specifically address brachytherapy (radiotherapy delivered from internal/implanted sources), particle therapy (e.g. protons) or therapeutic radioisotopes.

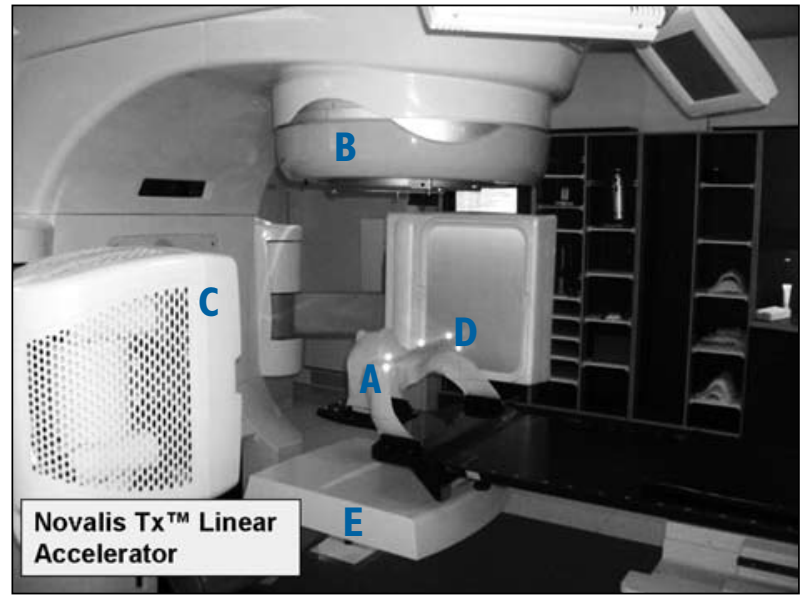

FIGURE I Conventional medical linear accelerator. The patient (illustrated by a thermoplastic immobilisation mask, A) lies on the robotic treatment couch that can be moved in six directions. The gantry head (B) rotates around the patient. Just before the photon treatment beam exits the gantry head it is shaped by the multi-leaf collimator. To position the patient correctly, in-room imaging technologies include gantry-mounted $\mathrm{X}$-rays and cone beam computed tomography (C), infrared surface markers $(D)$ and megavoltage imaging $(E)$.

Figure I illustrates the design of a conventional linear accelerator and shows the treatment couch on which the patient is positioned. Electrons are accelerated along a waveguide before colliding with a metal target and releasing high-energy mega-voltage $\mathrm{X}$-ray photons that can penetrate tissues and reach tumours inside the body. The photons exit from the gantry head, which can be rotated around the patient to deliver RT intermittently from discrete angles, or continuously using partial or complete revolutions (arcs) that encircle the patient. Individual beams summate in the tumour to deliver the desired dose that can vary with tumour type, stage and 


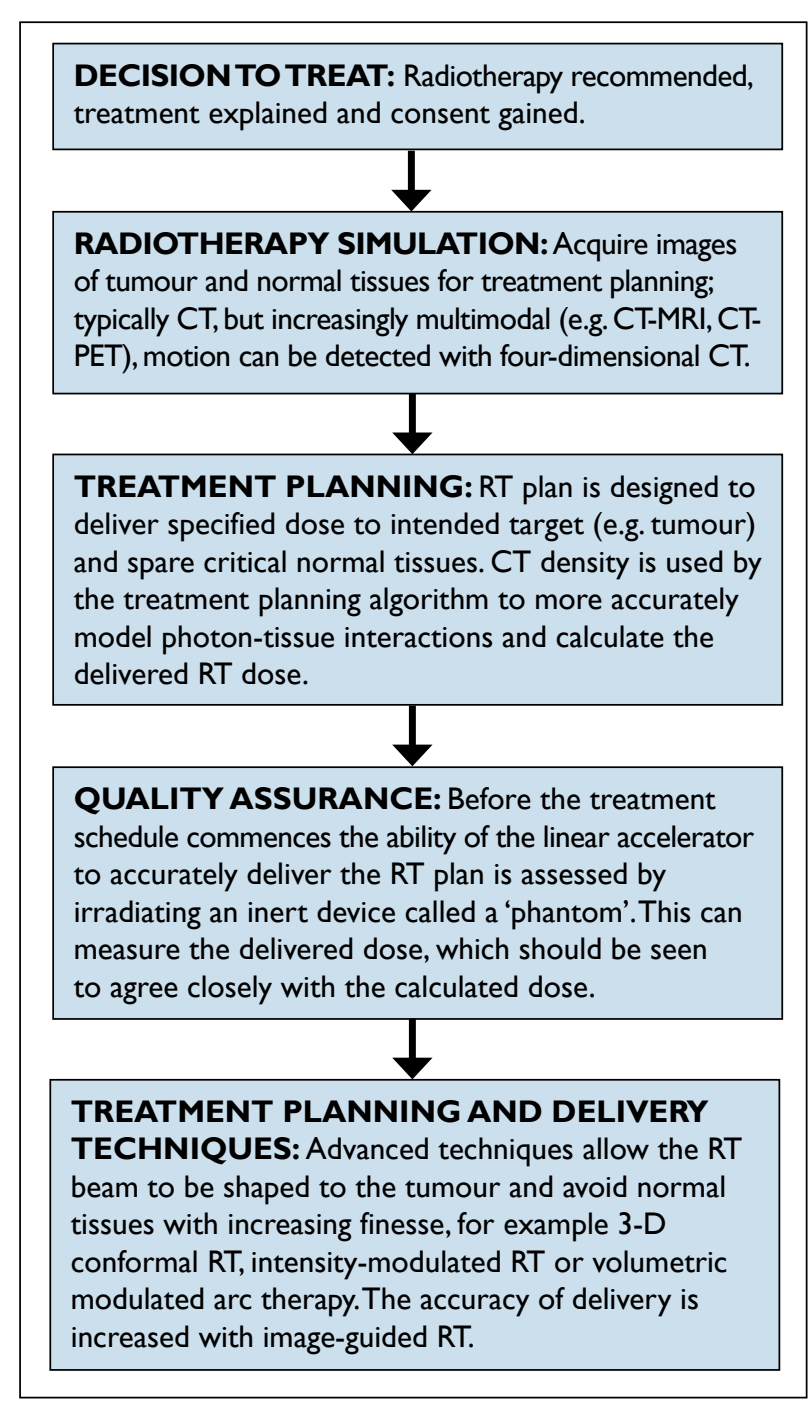

FIGURE 2 An outline of the radiotherapy process. Key personnel include therapy radiographers, treatment planners, radiotherapy physicists, radiation oncologists, administrative staff and treatment nurses.

clinical indication. Tumour eradication often requires high doses of RT, but critical normal tissues such as spinal cord or bowel that are sensitive to the damaging effects of ionising RT are frequently located close to the tumour and limit the total dose that can be delivered to it.

\section{THE RADIOTHERAPY PROCESS}

The RT process is summarised in Figure 2. The main components are treatment simulation, planning, quality assurance and delivery. Simulation is the acquisition of treatment planning images that will be used in the design of the RT treatment plan. In determining where the radiation dose is to be deposited, the RT plan takes into account the location of the target (e.g. tumour) and normal tissues, the prescribed radiation dose and the relative radiation tolerance of specific organs at risk. The images need to be obtained with the patient in the treatment position so that the spatial geometry of tumour and normal tissues is correct. If necessary, the patient is immobilised in this position using external fixation systems that increase the accuracy and precision of treatment delivery. Depending on the treatment site, positioning accuracy of less than one millimetre may be achievable. Methods of fixation include thermoplastic shells moulded to fit the relevant part of the patient's body and fixed to the treatment couch, which are commonly used in patients being treated for head and neck or brain cancer (Figure I), and bags filled with small polystyrene beads that form a customised cradle to support and hold the patient in the desired position when the patient lies on them and the air is evacuated. The latter are more commonly used for patients undergoing treatments in the thorax, abdomen or pelvis.

As radiotherapy treatment planning (RTP) requires the correct and precise identification of tumour and normal tissues, it is now usually based on volumetric threedimensional computed tomography (CT) images rather than two-dimensional radiography or limited crosssectional images. In addition to detailed anatomical information, CT scans contain electron density information for each tissue (can be correlated to Hounsfield units). Developments in RTP computer algorithms now allow them to account for heterogeneity in this density when they model the behaviour of X-ray photon beams passing through different tissues in the body.This means that they can more accurately predict the actual delivered dose to normal tissues and tumours in the final treatment plan.

\section{TREATMENT PLANNING AND DELIVERY}

The treatment volume and relevant normal tissues need to be accurately identified. Once the planning CT scan has been acquired, these structures are contoured on it using tools contained in the RTP system. Although high-quality three-dimensional CT scans help, target delineation remains prone to inter-observer variation and is one of the weaker links in the RT process. This is one reason for growing interest in automated and semi-automated tumour delineation (e.g. contouring based on a specified standardised uptake value [SUV] or percentage of maximum SUV, in the case of positron emission tomography $[\mathrm{PET}]$ imaging). However, at the present time, this has yet to enter routine clinical use. The validation of tumour segmentation algorithms is complex and may necessitate detailed radiology-pathology correlation studies.

There is also substantial effort being invested in normal tissue segmentation, which can be a time-consuming process. If the tumour is better visualised on modalities other than $\mathrm{CT}$, such as magnetic resonance imaging (MRI) or fluorodeoxyglucose (FDG) PET-CT, the images from these can often be imported into the RTP system and fused with the planning CT scan using rigid or non-rigid registration. The visible gross tumour volume (GTV) can then be contoured with the aid of multimodal imaging (Figure 3). ${ }^{6}$ If possible, all additional studies are also 


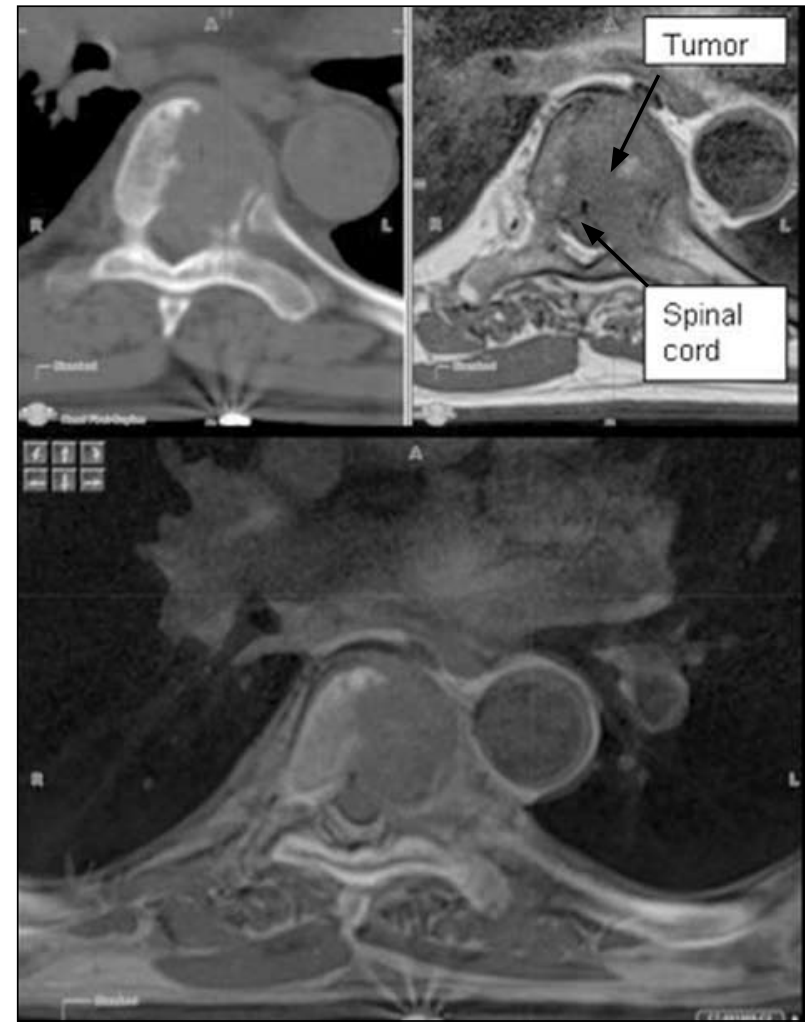

FIGURE 3 Multimodal imaging datasets can be imported into the radiation treatment planning system and co-registered to better delineate the tumour and normal tissues. In this example of CT (top left) and MRI (top right) fusion in the spine, the spinal cord and tumour are better seen on the MRI. When fused (bottom), the added detail from the MRI can be incorporated into the CT-based contours of the tumour and critical structures.

obtained in the treatment position using standardised protocols. In the case of MRI scans, these may need to be corrected for geometric distortion. Imaging modalities such as PET afford the possibility of identifying regions of different metabolic activity within the GTV. It has been postulated that some of these sub-volumes may be more resistant to the effects of RT than others and benefit from higher RT doses. This strategy, termed dose painting, has been made technically possible by advances in RT treatment planning and delivery methods (see below), but it is not currently in routine clinical use. ${ }^{7}$ Factors to be established in various tumour sites include the spatiotemporal stability of these sub-volumes, their validation as appropriate targets for dose escalation and the amount of additional RT dose that needs to be delivered.

Radiotherapy beams are frequently used to target the tumour from multiple angles. In order to avoid exceeding the radiation tolerance of normal tissues, it is desirable that the shape of the beam and the high-dose RT volume conform to the tumour profile. Beam shaping to match the tumour profile is typically achieved with a multi-leaf collimator, a computer-controlled device that is located in the gantry head (Figure I). It consists of two opposing sets of 2.5-10 mm-wide leaves, each of which can be positioned independently to allow for rapid and precise changing of the beam shape. This is known as threedimensional conformal RT (3DCRT) ${ }^{8}$ and can be combined with other strategies to further limit the high-dose RT region to the tumour. For example, the number of radiotherapy treatment beams can be increased from the 3-5 commonly used, up to 10-15. In addition, by methods including moving the multi-leaf collimator (MLC) leaves across the radiotherapy beam the photon intensity (fluence) can be varied, greatly increasing the ability to conform RT dose to complex target shapes and avoid normal tissues, even when they are partially or completely encircled. This is referred to as intensity-modulated RT (IMRT). ${ }^{\text {? }}$

Recent developments have combined new RT planning algorithms with the ability to deliver IMRT in a continuous arc around the patient whilst simultaneously varying the gantry speed and the radiation dose rate. RapidArc ${ }^{\mathrm{Tm}}$ is an example of what has been called volumetric-modulated arc therapy (VMAT). ${ }^{10}$ Although it does not always result in gains in the quality of treatment plans over conventional IMRT, VMAT can increase the freedom available to the RTP system and it may also help to increase the speed of treatment delivery. In some situations this may help to reduce patient movement which could compromise treatment accuracy.

\section{ACCOUNTING FOR UNCERTAINTIES}

Geometric margins are used to account for uncertainties in the RT process and are added to the GTV to create the planning target volume (PTV), which by convention denotes the actual treatment target. Margins can be used to account for microscopic tumour extension that cannot be identified on imaging, tumour motion not identified by standard fast CT imaging of moving tumours or imprecision in patient positioning during treatment sessions. Although margins have typically been based on population data, recent efforts have focused on creating patient-specific margins for more individualised RT plans. The impact of margins on the final treatment volume is illustrated by assuming that the PTV approximates a sphere, in which case its volume is proportional to the radius to the power 3.This means that a small reduction in radial margins can substantially reduce the PTV volume. Advances in technology (e.g. fourdimensional CT and image-guided RT, see below) are helping to reduce uncertainty and mean that some margins can now be individualised. This can facilitate margin reduction and help to reduce the PTV volume, which makes it more feasible to escalate the RT dose to the tumour to try to improve local control and cure rates.

\section{IMAGING TUMOUR MOTION WITH FOUR- DIMENSIONAL COMPUTED TOMOGRAPHY}

Many lung and upper abdominal tumours move, typically because of respiration. The use of conventional fast helical CT for RT planning results in snapshot images of 
the tumour, usually while the patient is in quiet respiration. This means that a mobile tumour will only be imaged at one point along its trajectory, which will remain unknown to the treatment planner. Although this uncertainty can be accounted for by adding generic margins, this approach may not be optimal. Advances in CT imaging mean that individual tumour motion can now be visualised with four-dimensional CT (4DCT), allowing patient-specific motion to be incorporated into the PTV." In essence, multiple CT images are acquired during quiet respiration and linked to specific phases of the breathing cycle, which is monitored throughout scanning. These phases can be sorted into the correct sequence and the images composited to identify tumour excursion during breathing (Figure 4).

Tumour motion can change if the breathing pattern changes; for example, the amplitude of tumour motion may increase with a larger tidal volume. This means that a treatment plan based on 4DCT imaging may not adequately treat the tumour if the breathing and therefore tumour motion during treatment differ appreciably from that during simulation. There are various approaches to making breathing more consistent, or reducing its impact on tumour motion. One approach is audio-visual coaching, which may make use of audio prompts like 'breathe in' and 'breathe out', and visual biofeedback such as a visible trace of real-time abdominal wall motion which the patient tries to keep at a constant amplitude. The aim of this is to standardise breathing and therefore tumour motion during simulation and treatment. ${ }^{22}$ Four-dimensional CT also images organs that move with respiration and can be used to provide greater confidence that these have been avoided during treatment planning. Other imaging modalities, including PET and MRI, can be acquired in 4D mode; however, at present, these are not as widely available as 4DCT.

\section{GATED RADIOTHERAPY}

The association between breathing and tumour motion makes it possible to design strategies to mitigate the effect of motion. For example, if the breathing cycle is monitored during RT simulation and treatment delivery, a plan can be developed that only treats the tumour during that part of the breathing cycle when it moves the least. Although this means that the tumour will only be treated for a part of each breathing cycle, potentially lengthening the overall treatment time, effectively limiting motion allows the size of the PTV to be reduced - an approach termed gated RT delivery. ${ }^{13}$ The trigger for RT delivery may be an easily accessible surrogate for the moving tumour such as chest wall excursion, or in some cases it may be decided to track the tumour itself or fiducial markers inserted inside or near to the tumour. If a surrogate is used then a consistent relationship between the motion of the surrogate and the location of the tumour is assumed, although in practice there is some uncertainty in this.

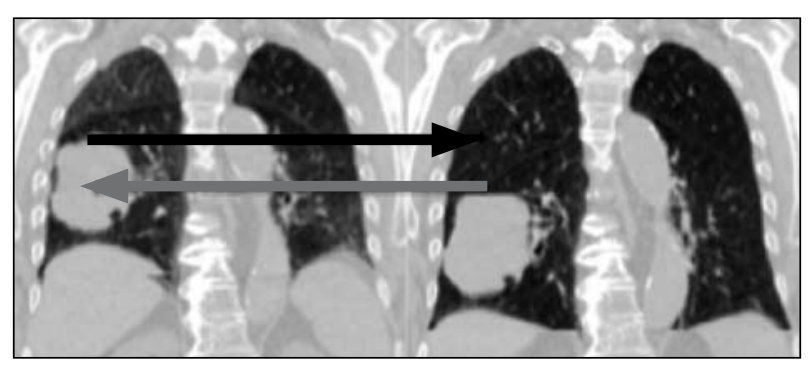

FIGURE 4 This shows the ability of 4DCT to identify motion. The left image illustrates the tumour as it appears during expiration (black arrow = superior border), while the right image demonstrates the location of the tumour during inspiration (grey arrow = superior border). The extent of motion and the gain in spatial information for mobile tumours is clearly visualised.

Alternative approaches to motion management include breath-hold techniques that intermittently suspend breathing and only deliver RT when there is no breathing and therefore minimal tumour motion, or tumourtracking techniques such as those that continuously modify the MLC leaf position to conform to the moving tumour (dynamic MLC) or real-time tumour tracking with a compact linear accelerator mounted on a robotic arm. Tracking a target throughout the breathing cycle allows a smaller PTV than accounting for motion in one large volume and may help to reduce normal tissue irradiation. Repeatedly suspending respiration for short periods (e.g. using a breath-hold technique) may not be practical for all patients, including those with marked dyspnoea and impaired lung function. Dynamic MLC tracking is not in routine clinical use in most clinics.

\section{IMAGE-GUIDED RADIOTHERAPY}

The highly conformal nature of advanced RT techniques and the presence of steep dose gradients near to critical normal tissues mean that high levels of accuracy in patient, tumour and critical organ positioning are required. It is insufficient to position the patient based solely upon external skin marks made during simulation. There are a number of ways in which positioning certainty can be increased, collectively termed imageguided RT (IGRT). ${ }^{14}$ Online IGRT is now commonly used, which means that the patient and tumour can be imaged before and during treatment delivery and their position can be corrected immediately. Typically, the IGRT image acquired at the treatment unit is overlaid on the planning image and matched using appropriate landmarks (e.g. spine) and/or the tumour itself (Figure 5).

Mismatch between the images due to incorrect positioning can be corrected by moving the treatment couch manually or robotically in at least three (vertical, longitudinal and lateral) and in some cases up to six directions (the addition of roll, pitch and yaw). Once the patient is correctly positioned, RT delivery can begin. As not all tumours are well visualised, it may be necessary to place 


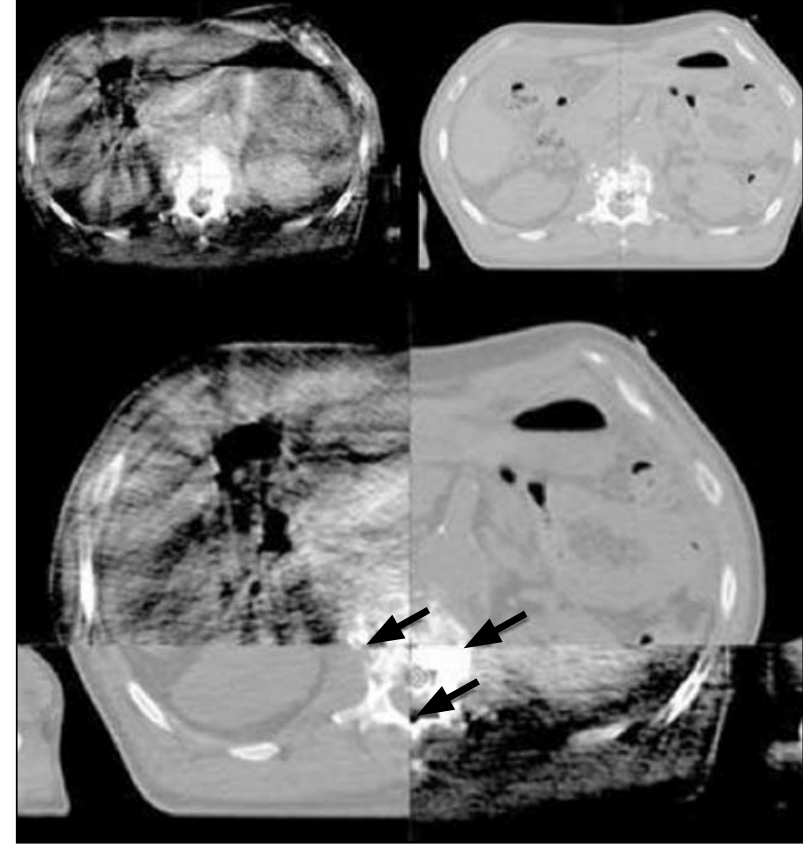

FIGURE 5 Image-guided RT using kilovoltage cone-beam CT is illustrated. Cone-beam CT images (top left) in this patient undergoing stereotactic spine RT are acquired before and during RT. The simulation CT images (top right) are available at the treatment unit and the two image sets are matched (lower image). During this process any discrepancy in localisation of the target or other selected landmarks can be quantified as a displacement in specific directions. This can then be corrected. Blending tools such as the one shown in the lower image are used to verify the alignment of structures in the matched images (arrows).

fiducial markers in or near to the tumour. A common example of this is gold seed markers in the prostate.

Image-guided RT can be based on two-dimensional technology, such as orthogonal kilovoltage $(\mathrm{kV})$ or megavoltage (MV) images, or three-dimensional data, such as $\mathrm{kV} C T$ from cone-beam $\mathrm{CT}$ (CBCT) units mounted on the linear accelerator as shown in Figure $I$. It is now also possible to track markers on the patient's surface or scan their body surface and identify when they have moved during treatment. The increased accuracy in patient positioning with IGRT means that a smaller margin is needed for any remaining positional uncertainty, reducing the PTV. A further advantage of IGRT technologies such as CBCT is that changes in tumour size or location which might invalidate the original treatment plan can be identified and prompt a new RT plan to be created - adaptive RT. ${ }^{15}$ Table I summarises these important advances in radiotherapy.

\section{THE IMPACT OF RECENT TECHNICAL ADVANCES}

\section{Improving patient outcomes}

Advances in RT technology are improving outcomes for patients and several examples of this are given in Table 2 . Technologies such as IMRT and VMAT are enabling new treatment approaches and are making it possible to offer
TABLE I Selected key changes that have taken place in radiotherapy over the past decade

\begin{tabular}{|l|l|l|}
\hline $\begin{array}{l}\text { Radiotherapy } \\
\text { process }\end{array}$ & I990s & Current state of art \\
\hline $\begin{array}{l}\text { Treatment } \\
\text { simulation } \\
\text { (acquisition } \\
\text { of images for } \\
\text { radiotherapy } \\
\text { planning) }\end{array}$ & $\begin{array}{l}\text { Two-dimensional } \\
\text { radiographs, } \\
\text { anatomical } \\
\text { landmarks, } \\
\text { conventional } \\
\text { CT scans }\end{array}$ & $\begin{array}{l}\text { Multimodality image } \\
\text { fusion using MRI and } \\
\text { PET-CT (Figure 3); } \\
\text { tumour and normal } \\
\text { tissue motion captured } \\
\text { by 4DCT (Figure 4) }\end{array}$ \\
\hline $\begin{array}{l}\text { Treatment } \\
\text { planning }\end{array}$ & $\begin{array}{l}\text { Simple 3D } \\
\text { programs to } \\
\text { model dose } \\
\text { deposited } \\
\text { by photon } \\
\text { beam without } \\
\text { accounting } \\
\text { for tissue } \\
\text { heterogeneity }\end{array}$ & $\begin{array}{l}\text { Planning programs to } \\
\text { better account for } \\
\text { variations in tissue } \\
\text { density and more } \\
\text { accurately model } \\
\text { dose deposition from } \\
\text { photons }\end{array}$ \\
\hline $\begin{array}{l}\text { Treatment } \\
\text { delivery }\end{array}$ & $\begin{array}{l}\text { 3D-conformal } \\
\text { RT with static } \\
\text { radiotherapy } \\
\text { beams shaped by } \\
\text { blocks or multi- } \\
\text { leaf collimator to } \\
\text { conform to the } \\
\text { tumour profile } \\
\text { (Figure I) }\end{array}$ & $\begin{array}{l}\text { Dynamic beam shaping } \\
\text { using multi-leaf } \\
\text { collimator (Figure I); } \\
\text { intensity-modulated } \\
\text { radiotherapy and } \\
\text { volumetric-modulated } \\
\text { arc therapies; gated RT } \\
\text { delivery; image-guided } \\
\text { RT (Figures I and 5); } \\
\text { adaptive RT }\end{array}$ \\
\hline
\end{tabular}

individual patients treatment where before this might not have been feasible. For example, certain regions within a treatment volume can be simultaneously boosted or spared.This might be the hippocampus in patients receiving cranial irradiation, with the aim of reducing neurocognitive side effects, ${ }^{22}$ or dose escalation to multiple low volume cerebral metastases in patients receiving whole-brain $\mathrm{RT}^{23}$ with the aim of improved local control and survival.

\section{Stereotactic body radiation therapy}

Although it is not new, ${ }^{24,25}$ recent advances in technology have facilitated SBRT, creating new treatment options and improving survival in selected patients. Conventional RT is frequently delivered in once-daily fractions of 1.8-2.75 Gray (Gy), Monday to Friday, for a total of 4-8 weeks. In comparison, SBRT uses a small number (e.g. 3-8) of large fractions (e.g. 20-7.5 Gy) to increase the biological potency of treatment. Normal tissues such as the spinal cord, bowel or central mediastinal structures are less tolerant of the doses used in SBRT.This means that PTV needs to be kept as small as possible, multiple beams or arcs are used to design compact and conformal high- and medium-dose regions that spare normal tissues, and treatment needs to be delivered with high precision. In this way, contemporary SBRT often incorporates all of the technologies discussed so far: 4DCT for mobile tumours, multimodal imaging for target delineation, advanced RT planning algorithms, IMRT/VMAT and IGRT. 
TABLE 2 Advances in RT technology are being used to improve patient-centered outcomes

\begin{tabular}{|l|l|l|l|}
\hline Technology & Benefit & Comments & Ref \\
\hline $\begin{array}{l}\text { CT-planning } \\
\text { and 3DCRT }\end{array}$ & $\begin{array}{l}\text { Improved survival } \\
\text { in NSCLC }\end{array}$ & $\begin{array}{l}\text { Minimum } \\
\text { requirements }\end{array}$ & 16 \\
\hline IMRT & $\begin{array}{l}\text { Parotid sparing } \\
\text { head and neck RT }\end{array}$ & $\begin{array}{l}\text { Reduced } \\
\text { xerostomia }\end{array}$ & 17 \\
\hline IMRT & $\begin{array}{l}\text { Dose escalation } \\
\text { and rectal sparing in } \\
\text { prostate cancer RT }\end{array}$ & $\begin{array}{l}\text { Improved local } \\
\text { control and } \\
\text { biochemical } \\
\text { disease-free } \\
\text { survival }\end{array}$ & 18 \\
\hline IMRT & For breast RT & $\begin{array}{l}\text { Reduced acute } \\
\text { skin toxicity }\end{array}$ & 19 \\
\hline $\begin{array}{l}\text { Gated RT } \\
\text { delivery }\end{array}$ & $\begin{array}{l}\text { For locally advanced } \\
\text { NSCLC }\end{array}$ & $\begin{array}{l}\text { Relative sparing } \\
\text { of lung tissue } \\
\text { facilitates dose } \\
\text { escalation }\end{array}$ & 20 \\
\hline SBRT & $\begin{array}{l}\text { For early-stage } \\
\text { NSCLC }\end{array}$ & $\begin{array}{l}\text { Higher survival } \\
\text { rates than } \\
\text { conventional RT } \\
\text { in meta-analysis }\end{array}$ & 21 \\
\hline
\end{tabular}

Stereotactic body RT in early stage NSCLC gives substantially better outcomes than conventional RT in nonrandomised comparisons ${ }^{21}$ and it has become a paradigm for the technique. Because lung SBRT has historically been recommended for patients who are medically inoperable, significant co-morbidities compromise overall survival but local control rates of about $90 \%$ are possible, as much as two to three times those obtained with conventional RT. However, there are data from Japan on medically operable patients who have undergone SBRT and achieved survival rates comparable to surgical resection. ${ }^{26}$ There is now a randomised study ('ROSEL') under way in the Netherlands comparing lung SBRT and surgery in patients with medically operable stage I NSCLC.

Modified dose/fractionation schedules are required for central tumours because midline structures including the oesophagus, trachea and bronchi are susceptible to damage from large fraction sizes that are unforgiving to normal tissues. Vigilance is also required for specific patterns of normal tissue toxicity that may be seen postSBRT; for example, rib fracture or chest wall pain can sometimes occur after treating tumours close to the chest wall. Stereotactic body RT can also be used in sites other than the lung; local control rates above $90 \%$ and high rates of analgesia have been reported for patients with spine metastases ${ }^{27}$ and recently published data on the use of SBRT for patients with one to three hepatic metastases and median follow-up of 16 months showed actuarial local control of $92 \%$ at two years. ${ }^{28}$

\section{New platforms for radiation delivery}

There are now several different advanced linear accelerators available, including the TomoTherapy ${ }^{\circledR}$,
CyberKnife $^{\circledR}$ and Novalis $\mathrm{Tx}^{\mathrm{TM}}{ }^{\text {systems. }}{ }^{29-31}$ Although these may be designed for specific applications such as IMRT, IGRT and SBRT, they are all capable of delivering high precision mega-voltage photon radiotherapy.

\section{THE CHALLENGES OF TECHNOLOGICAL CHANGE}

Side by side with the rapid development of new technologies and their entry into the clinic is a need for robust clinical data with which to describe and predict the effects of treatments on normal tissues and tumours. At the present time this means that patients need to be adequately followed up for expected and unexpected toxicity that may take many years to develop. For example, there have been cautionary notes that the larger volumes of low-dose RT associated with IMRT or VMAT may be associated with higher rates of RT-related cancers, especially in tumour sites associated with long-term survival..$^{32}$ More detailed knowledge of such factors will mean that they can be taken into account during RT treatment planning and management recommendations.

Technologies continuously evolve and so effective approaches to allow the timely evaluation of competing products are needed. It is perhaps relevant to distinguish between individual vendors' technologies in the same class, new classes of technology and new clinical treatments. Although frequently considered the standard for clinical comparisons, the need to gather randomised data for new technologies per se is debatable. ${ }^{33}$ Apart from financial and time implications, the ethics of study design would require that there was equipoise between new and older technologies, and consideration given as to whether all new technologies should be evaluated equally and whether they should be subjected to randomised testing across all clinical scenarios. Furthermore because technology moves on quickly, lengthy studies could easily be rendered outdated and provide an inadequate return on patient altruism and societal resources.

There are several possible non-randomised approaches to evaluating new technologies that may merit consideration in specific scenarios. For example, surrogate endpoints such as RT treatment plan dosimetry, treatment delivery time and treatment efficiency are gaining in popularity. Cost-benefit metrics have also been used. Radiation therapy probably accounts for a small fraction of the total cost of cancer care: a 2001 assessment estimated that external RT accounted for about $5 \%$ of the total oncology spend in Sweden. ${ }^{34}$ Initial costs for new technologies could add to this expenditure, but if they improve efficiency and outcome and lower toxicity, they could also reduce overall costs.

Although cost-benefit analysis is a potential tool for technology assessment, it is challenging, and deriving accurate and complete costs takes time, necessitating extended follow-up and considerable resources. Real- 
world confounders will include falling costs over time, cost sharing between institutions and negotiable prices and technology. Accurately representing these factors is a formidable challenge. Prospective cohort studies and treatment registries may be a practical means of gathering toxicity data, but more immediate and important for individual clinics is acquiring data on their own patterns of failure (documenting where tumours have recurred or progressed), treatment toxicity and survival, all of which will help to inform the efficacy and safety of new technologies and treatments, and ultimately aid clinical teams in making management recommendations to their patients. Additional work is required to develop robust criteria and frameworks for the evaluation of new technologies.

When introducing new RT technologies into the clinic, challenges that are common to many change and transformation projects are encountered. These include operating in a resource-limited environment, getting the team right, having senior management buy-in, communicating and creating a vision, setting a challenging timeline and developing resilience. The organisational response to such factors may be among the most important variables in determining whether a new technology is successfully implemented. ${ }^{35}$ Rapid technological change mandates vigilance to maintain the historically favourable safety profile of RT. Effective communication and robust data transfer processes have been identified as important factors in RT safety and new treatments with a reduced margin for error reinforce the pivotal role of quality assurance in the RT chain and necessitate optimal design of humantechnology interfaces..$^{36}$ Robust reporting mechanisms are needed to obtain accurate estimates of the incidence of adverse events and to ensure rapid and appropriate action if safety concerns are identified.

\section{REFERENCES}

I Erridge SC, Featherstone C, Chalmers R et al. What will be the radiotherapy machine capacity required for optimal delivery of radiotherapy in Scotland in 2015? Eur J Cancer 2007; 43:1802-9. doi:10.1016/j.ejca.2007.05.022

2 Fairchild A, Harris K, Barnes E et al. Palliative thoracic radiotherapy for lung cancer: a systematic review. J Clin Oncol 2008; 26:400 I-II. doi:I0.1200/JCO.2007.15.3312

3 Slotman B, Faivre-Finn C, Kramer G et al; EORTC Radiation Oncology Group and Lung Cancer Group. Prophylactic cranial irradiation in extensive small-cell lung cancer. N Engl J Med 2007; 357:664-72. doi:10.1056/NEJMoa07/780

4 Butturini G, Stocken DD, Wente MN et al; Pancreatic Cancer Meta-Analysis Group. Influence of resection margins and treatment on survival in patients with pancreatic cancer: meta-analysis of randomized controlled trials. Arch Surg 2008; 143:75-83. doi:10.100I/archsurg.2007.17

5 Thwaites DI, Tuohy JB. Back to the future: the history and development of the clinical linear accelerator. Phys Med Biol 2006; 5I:R343-62. doi:I0.1088/003 I-9/55/5 I/I3/R20

6 Kessler ML. Image registration and data fusion in radiation therapy. BrJ Radiol 2006; 79:S99-108. doi:10.1259/bjr/70617/64

\section{CONCLUSION}

There have been rapid technical developments in radiation oncology that are already opening up new treatment options for patients, playing a role in redefining management paradigms and pushing the boundaries of what is possible. Some of these advances have already been shown to improve patient outcomes. However, it is clear that they are only one part of the patient's global management, and specific challenges need to be overcome to allow the effective integration of new technologies into the clinic so that their full potential can be realised. At the same time the overall process from diagnosis to intervention needs to be designed so that disease progression during this period does not threaten to negate advances in therapy. ${ }^{37}$

\section{KEY POINTS}

- Radiotherapy (RT) is used in the management of about $50 \%$ of cancer patients.

- The RT process includes simulation, planning, quality assurance, treatment delivery and follow-up.

- New technologies and treatments can help to facilitate normal tissue sparing and increase the tumour dose in order to improve patient outcomes.

- Developments in radiation oncology include fourdimensional CT scanning, image-guided RT, intensitymodulated RT and stereotactic body RT.

- Organisational factors and project management are important in the successful implementation of new technologies and treatments.

- Technological advances are one facet of patient treatment. Direct patient care, implementing optimum treatment schedules and the design of the overall patient journey remain of the utmost importance.

7 Ling CC, Humm J, Larson S et al. Towards multidimensional radiotherapy (MD-CRT): biological imaging and biological conformality. Int J Radiat Oncol Biol Phys 2000; 47:55I-60. doi:I0.1016/S0360-3016(00)00467-3

8 Ling CC, Fuks Z. Conformal radiation treatment: a critical appraisal. Eur J Cancer 1995; 31:799-803. doi:10.1016/09598049(95)00088-Z

9 Yu CX, Amies CJ, Svatos M. Planning and delivery of intensitymodulated radiation therapy. Med Phys 2008; 35:5233-4I. doi:I0.III8/I.3002305

10 Palma DA, Verbakel WF, Otto $\mathrm{K}$ et al. New developments in arc radiation therapy: a review. Cancer Treat Rev 2010 Feb 22. [Epub ahead of print]

II Keall P. 4-dimensional computed tomography imaging and treatment planning. Semin Radiat Oncol 2004; 14:8I-90. doi:I0.1053/j.semradonc.2003.10.006

12 Haasbeek CJ, Spoelstra FO, Lagerwaard FJ et al. Impact of audiocoaching on the position of lung tumors. Int J Radiat Oncol Biol Phys 2008; 71:I I 18-23. doi:10.1016/j.jijobp.2007.II.06 I

13 Jiang SB. Radiotherapy of mobile tumors. Semin Radiat Oncol 2006; 16:239-48. doi:10.1016/j.semradonc.2006.04.007 
14 Dawson LA, Jaffray DA. Advances in image-guided radiation therapy J Clin Oncol 2007; 25:938-46. doi: I0.1200/JCO.2006.09.95I5

I5 Tanyi JA, Fuss MH.Volumetric image-guidance: does routine usage prompt adaptive re-planning? An institutional review. Acta Oncol 2008; 47: |444-53. doi: I0.1080/0284|86080227974|

I6 Liao ZX, Komaki RR, Thames HD Jr et al. Influence of technologic advances on outcomes in patients with unresectable, locally advanced non-small-cell lung cancer receiving concomitant chemoradiotherapy. Int J Radiat Oncol Biol Phys 2010; 76:775-8I. doi:10.1016/j.ijrobp.2009.02.032

I7 Eisbruch A. Intensity-modulated radiation therapy in the treatment of head and neck cancer. Nat Clin Pract Oncol 2005; 2:34-9. doi: $10.1038 /$ ncponc0058

I8 Cahlon O, Hunt M, Zelefsky MJ. Intensity-modulated radiation therapy: supportive data for prostate cancer. Semin Radiat Oncol 2008; 18:48-57. doi:10.1016/j.semradonc.2007.09.007

19 Pignol JP, Olivotto I, Rakovitch E et al. A multicenter randomized trial of breast intensity-modulated radiation therapy to reduce acute radiation dermatitis. J Clin Oncol 2008; 26:2085-92. doi:I0.1200/JCO.2007.15.2488

20 Rosenzweig KE, Yorke E, Amols $\mathrm{H}$ et al. Tumor motion control in the treatment of non small cell lung cancer. Cancer Invest 2005; 23:129-33.

2I Grutters JP, Kessels AG, Pijls-Johannesma M et al. Comparison of the effectiveness of radiotherapy with photons, protons and carbon-ions for non-small cell lung cancer: a meta-analysis. Radiother Oncol 2009 Sep 3. [Epub ahead of print]

22 Ghia A,Tomé WA, Thomas $\mathrm{S}$ et al. Distribution of brain metastases in relation to the hippocampus: implications for neurocognitive functional preservation. Int J Radiat Oncol Biol Phys 2007; 68:97I-7. doi:10.1016/j.ijrobp.2007.02.016

23 Lagerwaard FJ, van der Hoorn EA, Verbakel WF et al.Whole-brain radiotherapy with simultaneous integrated boost to multiple brain metastases using volumetric modulated arc therapy. Int J Radiat Oncol Biol Phys 2009; 75:253-9. doi:I0.I016/j.jirobp.2009.03.029

24 Leksell L. The stereotaxic method and radiosurgery of the brain Acta Chir Scand 1951; 102:316-9.

25 Blomgren H, Lax I, Näslund I et al. Stereotactic high dose fraction radiation therapy of extracranial tumors using an accelerator
Clinical experience of the first thirty-one patients. Acta Oncol 1995; 34:86I-70. doi:I0.3109/0284I869509|27I97

26 Onishi H, Shirato H, Nagata $Y$ et al. Hypofractionated stereotactic radiotherapy (HypoFXSRT) for stage I non-small cell lung cancer: updated results of 257 patients in a Japanese multi-institutional study. JThorac Oncol 2007; 2:S94-100. doi:I0.1097/JTO.0b0I3e318074de34

27 Gerszten PC, Burton SA, Ozhasoglu C et al. Radiosurgery for spinal metastases: clinical experience in 500 cases from a single institution. Spine (Phila Pa 1976) 2007; 32:193-9.

28 Rusthoven KE, Kavanagh BD, Cardenes $\mathrm{H}$ et al. Multi-institutional phase I/II trial of stereotactic body radiation therapy for liver metastases. J Clin Oncol 2009; 27:I572-8. doi:10.1200/JCO.2008.19.6329

29 Mackie TR. History of tomotherapy. Phys Med Biol 2006; 5 I:R42753. doi:I0.1088/003 I-9I55/5I/I3/R24

30 Adler JR Jr, Chang SD, Murphy MJ et al.The Cyberknife: a frameless robotic system for radiosurgery. Stereotact Funct Neurosurg 1997 69:124-8. doi: I0.1 I59/000099863

3I Teh BS, Paulino AC, Lu HH et al.Versatility of the Novalis system to deliver image-guided stereotactic body radiation therapy (SBRT) for various anatomical sites. Technol Cancer Res Treat 2007; 6:347-54.

32 Hall EJ. The inaugural Frank Ellis Lecture - latrogenic cancer: the impact of intensity-modulated radiotherapy. Clin Oncol ( $R$ Coll Radiol) 2006; I8:277-82. doi:I0.1016/j.clon.2006.02.006

33 Bentzen SM. Randomised controlled trials in health technology assessment: overkill or overdue? Radiother Oncol 2008; 86:142-7. doi:10.1016/j.radonc.2008.01.012

34 Norlund A; SBU Survey Group. Costs of radiotherapy. Acta Oncol 2003; 42:4II-5. doi: I0.1080/0284I8603 I00 III40

35 Sirkin HL, Keenan P, Jackson A. The hard side of change management. Harvard Business Review 2005; 83:108-18.

36 Amols HI. New technologies in radiation therapy: ensuring patient safety, radiation safety and regulatory issues in radiation oncology. Health Phys 2008; 95:658-65. doi:I0.I097/0I.HP.0000326334.64242.46

37 O'Rourke N, Edwards R. Lung cancer treatment waiting times and tumour growth. Clin Oncol ( $R$ Coll Radiol) 2000; |2:|4|-4. doi:10.1053/clon.2000.9139

\section{SELF-ASSESSMENT QUESTIONS}

I. The vast majority of radiotherapy (RT) treatments use:

A. External beam RT.

B. Brachytherapy.

C. Particle therapy.

D. Therapeutic radioisotopes.

E. Intra-operative RT.

\section{Which one of the following is true of RT?}

A. Palliative radiotherapy cannot improve survival.

B. Radiotherapy doses are rarely limited by normal tissues surrounding the tumour.

C. Modern radiotherapy planning is based on twodimensional images.

D. Radiotherapy beams are frequently used to target the tumour from multiple angles.

E. Radiotherapy beams cannot be shaped to avoid normal tissues and conform to the tumour.
3. Some tumours (e.g. those in the lung and upper abdomen) can move during breathing. Which one of the following statements is false?

A. Tumour motion can increase the target volume that needs to be irradiated.

B. Other imaging modalities, including positron emission tomography and magnetic resonance imaging, can be acquired in four-dimensional (4D) mode. However, at present these are not as widely available as 4D computed tomography.

C. In general, tumour motion is reduced by an increase in the depth of respiration.

D. Individual tumour motion can now be visualised with 4D computed tomography scanning.

E. Audio-visual respiratory coaching, gated RT, tumour tracking and RT delivery during breath-hold are all techniques that have been designed to be used in the treatment of mobile tumours. 
4. Which one of the following statements relating to improvements in patient outcomes is false?

A. Intensity-modulated RT has been associated with increased acute skin toxicity in patients with breast cancer.

B. Non-randomised data show that stereotactic body RT has been associated with improved outcomes for medically inoperable early-stage non-small-cell lung cancer.

C. Intensity-modulated RT can reduce xerostomia in patients with head and neck cancer.

D. Three-dimensional CT planning and conformal RT has been associated with improved outcomes in non-smallcell lung cancer.

E. New treatments may be associated with new patterns of toxicity requiring vigilance during follow-up.
5. Which two of the following are challenges associated with new RT technologies?

A. Radiotherapy already accounts for a large proportion of cancer care costs and new technologies will only increase this.

B. Technology assessment methods need to be able to adapt to rapid change while taking into account the possibility of toxicity arising many years post treatment.

C. Most new designs of linear accelerator deliver fundamentally different types of RT with an expectation of substantially different patient outcomes between such devices.

D. Technological advances mean that improvements in the patient pathway from diagnosis to intervention become less important.

E. Organisational and project management factors may be among the most important determinants of success when implementing new technologies and treatments.

For the answers, please turn to page 190.

\section{INVITATION TO SUBMIT PAPERS}

We would like to extend an invitation to all readers of The Journal of the Royal College of Physicians of Edinburgh to contribute original material, especially to the clinical section. The JRCPE is a peer-reviewed journal with a circulation of 8,000 . Its aim is to publish a range of clinical, educational and historical material of crossspecialty interest to the College's international membership.

The JRCPE is currently indexed in Embase, Google Scholar and the Directory of Open Access Journals, and the History section is included in Medline. The editorial team is keen to continue to improve both the quality of content and its relevance to clinical practice for Fellows and Members. All papers are subject to peer review and our turnaround time for a decision averages only eight weeks.

We would be pleased to consider submissions based on original clinical research, including pilot studies. The JRCPE is a particularly good forum for research performed

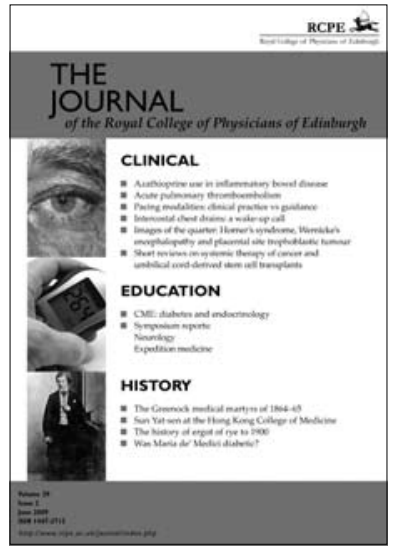
by junior doctors under consultant supervision. We would also consider clinical audits where the loop has been closed' and a demonstrable clinical benefit has resulted.

For further information about submissions, please visit: http://www.rcpe.ac.uk/journal/contributers.php or e-mail editorial@rcpe.ac.uk.Thank you for your interest in the College's journal.

The editorial team,

The Journal of the Royal College of Physicians of Edinburgh 